\title{
Um Olhar para a Prática Pedagógica de Professores que Ensinam Estatística: por uma Formação Crítica e Contextualizada
}

\section{A look at the Pedagogical Practice of Teachers who Teach Statistics: for a Critical and Contextualized Formation}

\author{
Alyson Fernandes de Oliveira ; Dalva Eterna Gonçalves Rosa*b \\ ${ }^{a}$ Instituto Federal de Goiás - Campus Anápolis. GO, Brasil. \\ ${ }^{b}$ Universidade Federal de Goias, GO, Brasil. \\ *E-mail: dalvaeterna@gmail.com
}

\begin{abstract}
Resumo
A formação de professores é um processo fundamental para que ocorram mudanças na educação contemporânea. Por meio dela, profissionais são preparados para lidar com os mais diversos desafios no campo educacional e têm a possibilidade de realizar a análise e a reflexão acerca da prática pedagógica. Uma temática que carece de estudos, devido a sua intensa aplicabilidade no meio social, é a Estatística, ciência capaz de explicar fenômenos da sociedade e como estes ocorrem nas relações humanas. Nesse sentido, este artigo tem como pretensão compreender como a Estatística vem sendo trabalhada pelos professores no Ensino Médio, visando à importância de uma formação continuada em Educação Estatística. Em uma abordagem qualitativa, os dados da pesquisa foram obtidos por meio de observações de aulas em duas escolas estaduais do município de Anápolis - GO, de entrevistas semiestruturadas com os três professores participantes e da análise dos seus planos de aula, os quais foram sistematizados e interpretados de acordo com a Análise de Conteúdo. Os resultados obtidos permitem considerar que, por mais que os professores trabalhem, em sala de aula, todos os conteúdos estatísticos propostos no currículo do Estado, esses não são abordados de forma contextualizada, o que impossibilita uma formação crítica dos estudantes. Assim, evidencia-se a necessidade de cursos de formação continuada de professores com enfoque na Educação Estatística crítica e contextualizada, visto que muitos docentes não foram formados nessa perspectiva.
\end{abstract}

Palavras-chave: Formação de Professores. Educação Estatística. Contextualização. Crítica.

\begin{abstract}
Teacher training is a fundamental process for changes in contemporary education to occur. Through it, professionals are prepared to deal with the most diverse challenges in the educational field and have the possibility to carry out the analysis and reflection on the pedagogical practice. A subject that needs studies, due to its intense applicability in the social environment, is Statistics, a science capable of explaining phenomena in society and how they occur in human relationships. In this sense, this article aims to understand how Statistics has been worked by teachers in high school, aiming at the importance of continuing education in Statistical Education. In a qualitative approach, the research data were obtained through classroom observations in two state schools in the city of Anápolis - GO, through semi-structured interviews with the three participating teachers and through the analysis of their lesson plans, which were systematized and interpreted according to Content Analysis. The results obtained allow us to consider that, no matter how much the teachers work in the classroom, all the statistical contents proposed in the State curriculum are not approached in a contextualized way, which makes critical formation of students impossible. Thus, there is a need for continuing teacher education courses, with a focus on critical and contextualized statistical education, as many teachers were not trained in this perspective.
\end{abstract}

Keywords: Teacher training. Statistical Education. Contextualization. Criticism.

\section{Introdução}

Presente nos mais diversos setores da sociedade, a Estatística vem sendo grande aliada para resolver ou interferir criticamente nos problemas relacionados às diferentes áreas do conhecimento. Sua compreensão se faz necessária devido ao grande número de informações que nos cercam cotidianamente, às quais são representadas de diferentes formas e demandam a interpretação dos cidadãos.

Devido ao emprego da Estatística na sociedade contemporânea, é necessário que ela esteja presente no âmbito escolar, visto ser este um dos locais que possibilita ao indivíduo criar redes de relações sociais e interagir em sociedade. Por meio dessa interação social, na qual a Estatística se faz presente, os estudantes comunicam ideias, fazem estimativas e divulgam, de forma crítica, suas conclusões sobre inúmeras situações recorrentes da sociedade, construindo uma visão diferenciada de mundo ao desenvolver seu pensamento crítico e a capacidade de reflexão.

Para desempenhar o papel de cidadão crítico, que participa efetivamente do mundo do trabalho, das relações sociais, culturais e políticas de uma sociedade que se pauta no conhecimento e na comunicação constante, Lopes (2008) ressalta que o ensino da Estatística pode possibilitar que o estudante amplie suas capacidades críticas e autônomas. Assim, ele passa a apreender outros conceitos matemáticos tradicionalmente trabalhados no ambiente escolar, com o auxílio do professor, que atua como mediador do conhecimento ali produzido.

Concordamos com Giroux (1997) quando difunde a ideia de que os professores devem se tornar intelectuais 
transformadores, caso tenham a intenção de contribuir para que os estudantes sejam cidadãos ativos e críticos. Nessa conjuntura, o professor, por meio de sua prática pedagógica em sala de aula, auxiliará os estudantes a compreenderem os conceitos básicos da Estatística, assim como os levará a perceberem a relevância desses conceitos em situações cotidianas. Mediante o exposto, este artigo tem como proposta compreender como a Estatística vem sendo trabalhada pelos professores no Ensino Médio e discutir a importância de uma formação continuada na área de Matemática, com foco no ensino de Estatística na perspectiva da Educação Crítica.

\section{A Formação de Professores de Matemática e a Educação Estatística}

Com o objetivo de auxiliar na obtenção, organização e análise de dados que são indispensáveis para o conhecimento científico e social construídos em sociedade, a Estatística surge como a ciência responsável por explicar determinados fenômenos e as relações existentes entre estes, que são instituídas na humanidade. De acordo com Batanero et al. (2013), essa área de conhecimento é parte da nossa herança cultural e compreendê-la possibilitará aos cidadãos participar ativamente da sociedade em que vivem, visto que sua presença no mundo contemporâneo é uma realidade.

Uma das formas de levar a Estatística ao conhecimento de todos é por meio da escolarização. Essa ciência já faz parte do currículo educacional desde o estabelecimento dos Parâmetros Curriculares Nacionais (PCN) no ano de 1997 (Brasil, 1998), além de constar em outros documentos orientadores do Ensino Médio que foram publicados nos anos seguintes. Nos últimos anos, todo esse arsenal de orientações curriculares foi complementado com a Base Nacional Comum Curricular (BNCC), tanto para o Ensino Fundamental quanto para o Ensino Médio (Brasil, 2017, 2018), que aborda a Estatística dentro do componente curricular Matemática, tendo como intuito promover o contato do educando com essa ciência, desde o início de sua vida escolar. Além disso, a BNCC visa propiciar a compreensão das principais ideias matemáticas implícitas nas representações estatísticas, o propósito e a lógica das investigações estatísticas, bem como o processo de investigação e o desenvolvimento de aptidões que permitam ao estudante produzir e usufruir dos bens culturais, sociais e econômicos (Oliveira \& Rosa, 2020).

Um dos objetivos da Educação Estatística é romper com os obstáculos referentes ao processo de ensino e aprendizagem do conteúdo de Estatística. Tais obstáculos estão intrinsicamente ligados à busca do desenvolvimento crítico, político e social dos estudantes, que lidam com a Estatística e com a compreensão de sua aplicabilidade em situações cotidianas.

Mesmo que os conteúdos estatísticos estejam cotejados nos documentos curriculares nacionais, vê-se a ausência desses temas na formação inicial e continuada dos professores de matemática. Atualmente, nas matrizes curriculares dos cursos de licenciatura em Matemática, é ofertada a disciplina de Estatística e Probabilidade; porém, tal disciplina tem como foco o ensino formal, em que ganham destaque demonstrações de algoritmos, resolução de problemas sem uma abordagem contextual e a simples substituição de valores em fórmulas extensas para se chegar a um resultado. Lopes (2013) chama a atenção para a maneira como os cursos de formação inicial de professores de matemática estão lidando com o ensino de Estatística, ressaltando a importância de trabalhos pautados em projetos e de atividades que estejam relacionadas ao cotidiano dos alunos, de modo que façam sentido para eles.

Consideramos que os docentes constroem seus saberes e continuam em formação por meio das práticas desenvolvidas por eles no ambiente de atuação profissional. Tardif (2012, p. 237) salienta que esses professores “através de suas próprias experiências, tanto pessoais, quanto profissionais, constroem seus saberes, assimilam novos conhecimentos e competências e desenvolvem novas práticas e estratégias de ação". Ao pensar em uma prática diferente daquela já conhecida pelo docente em seu tempo de escola, na qual tinha seus professores como exemplo profissional e suas ações como certas a serem seguidas, compreendemos que o professor é o principal transformador de suas práticas (D’Ambrosio \& Lopes, 2015).

Quando o professor, teoricamente fundamentado, começa a refletir sobre a própria prática, a formação continuada passa a se estabelecer e ela se desenvolve a partir da busca contínua de melhores condições profissionais, em que novas práticas passam a serem desenvolvidas, por meio de situações didáticas pautadas nas vivências cotidianas (Fiorentini et al., 2002). Logo,

pensar sua formação significa pensá-la como um continuum de formação inicial e contínua. Entende, também, que a formação é, na verdade, autoformação, uma vez que os professores reelaboram os saberes iniciais em confronto com suas experiências práticas, cotidianamente vivenciadas nos contextos escolares. É nesse confronto e num processo coletivo de troca de experiências e práticas que os professores vão constituindo seus saberes como praticum, ou seja, aquele que constantemente reflete na e sobre a prática. (Pimenta, 1997, p. 11)

Acerca da formação inicial e continuada dos professores de Matemática em Educação Estatística, Estevam e Cyrino (2014) apresentam uma detalhada discussão das pesquisas brasileiras nessa área que, segundo eles, ainda são bem escassas; eles mostram que o conhecimento dos professores acerca da Estatística está em um nível básico no Brasil. Alguns autores brasileiros já discutem sobre a formação precária de professores em Educação Estatística (Pamplona \& Carvalho, 2011; Costa \& Nacarato, 2011; Costa \& Pamplona, 2011; Lopes, 2013). Com base nesses estudos, pode-se inferir que muitos desses professores não tiveram contato com a Estatística na graduação e os que já tiveram, o fizeram de forma técnica, não visando às possibilidades de um ensino voltado para a Educação Estatística Crítica. Assim, muitos professores acabam indo para as salas de aula ministrar 
assuntos dessa temática sem uma formação adequada e essa atitude reverbera no trabalho realizado por eles com esses conteúdos. Eles permanecem sem essa formação, por muito tempo, não buscando uma formação continuada que lhes possibilite mudar esse cenário.

O trabalho com a Educação Estatística nas escolas requer o desenvolvimento de uma postura diferenciada do professor, pois lidar com ideias de variabilidade, por exemplo, pode possibilitar aos estudantes observar o comportamento dos dados trabalhados e a relação destes com o cotidiano, de forma crítica e autônoma. E esse ainda é um grande desafio para os profissionais da educação, conforme descrito nas pesquisas de Costa (2012) e Viali (2008), que indicam que grande parte das dificuldades dos professores de Matemática ao trabalhar com os conteúdos de Estatística, em sala de aula, se deve ao fato de que esses se correlacionam com a realidade dos alunos e exigem, portanto, a contextualização.

Campos, Wodewotzki e Jacobini (2013, p. 25) abordam a importância de a Educação Estatística seguir uma perspectiva contextualizada, na qual:

(...) o entendimento dos conceitos básicos de Estatística deve preceder o cálculo. Antes de usar as fórmulas, os estudantes devem perceber a utilidade, a necessidade de uma certa estatística. (...) o estudante deve, primeiramente, compreender o contexto em que tal estudo será realizado, os objetivos do projeto e de que maneira as técnicas estatísticas contribuirão para a inferência dos resultados.

Dessa forma, vemos a importância de um trabalho pedagógico em que a Estatística seja contextualizada em sala de aula pelo professor, desassociada das fórmulas prontas e dos exercícios mecânicos. Ao abordar a Estatística relacionada ao cotidiano, o professor possibilita sua aproximação direta com o social de forma crítica, na qual a contextualização permite uma compreensão global do meio social pelo indivíduo, sendo esse um dos principais aspectos da educação estatística. Seguindo essa concepção, Wodewotzki e Jacobini (2004, p. 233) afirmam que a educação estatística se trata de “(...) um processo que favorece a contextualização das informações e oferece oportunidades relevantes para reflexões e para críticas, sobretudo quando se trata de informações de ordem social".

Trabalhar os conteúdos estatísticos na perspectiva contextualizada e crítica ainda se constitui como um desafio para os docentes, pois essa também não é uma realidade nos cursos de formação de professores. Lopes (2010, p. 48) enfatiza que esses conteúdos "ainda não têm sido prioridade na escola, nem nos programas de formação inicial e contínua de professores que ensinam Matemática" e, mediante essa realidade, não é suficiente que o professor adote metodologias de ensino que tornem os conteúdos relevantes aos estudantes, mas também é necessário que ele tenha domínio dos conceitos estatísticos a serem trabalhados em sala de aula (Samá, Cazorla \& Amorim, 2019).

\section{O Caminho Metodológico da Pesquisa}

Esta pesquisa segue uma abordagem qualitativa, visto que não temos a intenção de apresentar dados numéricos e suas representações, mas, sim, nossas interpretações dos dados com base na literatura que as fundamenta teoricamente. Esse tipo de abordagem nos possibilitou aprofundar a compreensão dos fenômenos da realidade estudada, como a ação de indivíduos em seus ambientes ou contextos sociais, e interpretar o modo como os próprios sujeitos dessa realidade se relacionam. Assim, além de envolver a coleta e a produção de dados descritivos, que foram por nós obtidos por meio do contato direto com a situação, essa abordagem visa enfatizar mais o processo do que o produto, preocupando-se em retratar a perspectiva dos participantes da pesquisa (Bogdan \& Biklen, 2006). A escolha dessa abordagem se justifica, ainda, por observarmos que, por meio da descrição dos dados construídos em nossa inserção no lócus de pesquisa, seria possível analisar as relações estabelecidas entre os sujeitos participantes, os conteúdos ensinados em sala de aula e o mundo em que esses sujeitos vivem, baseados em um processo de interações cotidianas. Além disso,

Parte de questões ou focos de interesses amplos, que vão se definindo à medida que o estudo se desenvolve, envolve a obtenção de dados descritivos sobre pessoas, lugares e processos interativos pelo contato direto do pesquisador com a situação estudada, procurando compreender os fenômenos segundo a perspectiva dos sujeitos, ou seja, dos participantes da situação em estudo. (Godoy, 1995, p. 58)

Esta pesquisa teve como cenário duas escolas estaduais do município de Anápolis - GO (denominadas escola X e $\mathrm{Y}$, para resguardar o anonimato), ambas situadas em bairros periféricos da cidade e que ofertam vagas para o Ensino Fundamental II e Ensino Médio para uma média de 600 a 1000 estudantes. Os sujeitos participantes da investigação foram selecionados devido ao fato de terem cargos efetivos na rede estadual de ensino, o que possivelmente não resultaria em um afastamento abrupto da pesquisa. Além desse motivo, buscamos professores que fossem formados em Matemática e lecionassem a disciplina na $3^{\mathrm{a}}$ série do Ensino Médio, considerando que o conteúdo de Estatística é abordado nessa série, de acordo com o currículo do estado de Goiás.

Ainda quanto aos professores, três aceitaram participar da pesquisa, sendo duas mulheres e um homem, os quais foram nomeados como P1, P2 e P3, a fim de resguardar suas identidades. Dois deles lecionam na escola X (P1 e P2), e um na escola Y (P3). O professor P1 é efetivo na rede estadual de ensino há mais de 20 anos e leciona somente nessa escola por todo esse tempo. Tem 45 anos de idade, é licenciado em Matemática e possui pós-graduação na área de ensino. P2 é efetiva na rede estadual de ensino há mais de 10 anos e também leciona na rede privada de ensino básico. Tem 35 anos de idade, é licenciada em Matemática e possui pós-graduação em Engenharia Civil. P3 é efetiva na rede estadual de ensino há mais de 10 anos e também leciona na rede privada de ensino 
superior. Tem 32 anos de idade, é licenciada em Matemática, mestre em Ciências e está cursando o doutorado na área de Educação.

Para a coleta e posterior produção dos dados, foram realizadas observações em uma turma de cada professor. O tipo de observação realizada é definido por Lakatos e Marconi (2003) como observação não participante, em que o pesquisador tem total contato com a comunidade ou realidade estudada, mas não se integra a ela; não se envolve nas situações, fazendo mais o papel de espectador; presencia os fatos, mas não participa deles. Logo, por meio de um olhar atento para a prática pedagógica do professor, buscamos compreender como os conteúdos referentes à Estatística estão sendo trabalhados em sala de aula.

As observações aconteceram em um bimestre letivo, com o total de doze aulas em cada uma das turmas dos professores; porém, nem todas elas ocorreram em sequência, devido a eventualidades no calendário escolar das instituições. Para registrar as observações realizadas, utilizamos um diário de campo, procurando descrever com riqueza de detalhes as ocorrências ao longo das aulas. Concordamos que tal instrumento é de grande importância para a coleta de dados e nos ajudou muito no registro de todos os acontecimentos e diálogos ocorridos em sala de aula entre os alunos e os professores, e no registro da prática pedagógica de cada professor em sala de aula.

De forma concomitante, realizamos entrevistas semiestruturadas com os três docentes participantes que é, segundo Triviños (2013, p. 146):

(...) aquela que parte de certos questionamentos básicos, apoiados em teorias e hipóteses, que interessam à pesquisa, e que, em seguida, oferecem amplo campo de interrogativas, fruto de novas hipóteses que vão surgindo à medida que se recebem as respostas do informante. Dessa maneira, o informante, seguindo espontaneamente a linha de seu pensamento e de suas experiências dentro do foco principal colocado pelo investigador, começa a participar na elaboração do conteúdo da pesquisa.

Com agendamento prévio, de acordo com a disponibilidade dos professores, as entrevistas foram concedidas individualmente, nas dependências da escola em que cada professor atua, sendo gravadas em áudio, com duração de, aproximadamente, vinte minutos. Na entrevista semiestruturada, o pesquisador, "pretendendo aprofundarse sobre um fenômeno ou questão específica, organiza um roteiro de pontos a serem contemplados, podendo, de acordo com o desenvolvimento da entrevista, alterar a ordem deles e, até mesmo, formular questões não previstas inicialmente" (Fiorentini \& Lorenzato, 2007, p. 121). Com o planejamento das entrevistas, buscamos compreender a visão dos docentes sobre o ensino de Estatística, nos detendo nos aspectos conceituais e nas relações com o dia a dia dos estudantes, bem como nos aspectos organizacionais, por meio do planejamento e de metodologias de ensino por eles utilizadas.

Com o intuito de compreender a forma como os conteúdos de Estatística são selecionados para serem trabalhados em sala de aula, optamos por realizar uma pesquisa documental, com base nos planos de aula dos professores. Esse tipo de pesquisa tem como fonte materiais ainda não tratados analiticamente ou que podem ser reelaborados conforme os objetivos da pesquisa (Moreira \& Caleffe, 2006; Gil, 2008).

Acreditamos ser importante que os professores rompam com o paradigma de que planejar seja um ato técnico e comecem a pensar sobre sua relevância para a formação social dos sujeitos envolvidos com esse plano, pois o planejamento didático consiste no processo de decisão e organização das atividades para o desenvolvimento do processo de ensino-aprendizagem. Logo, compete ao professor organizar intencionalmente as situações de ensino para que a aprendizagem seja significativa para o estudante. O plano de aula é um detalhamento do plano de ensino, um desdobramento de cada unidade temática organizado de forma lógica.

Ao findar as observações nas três turmas, solicitamos aos professores participantes da pesquisa que disponibilizassem seus planos de aula referentes aos conteúdos de Estatística. Esses planos foram elaborados no Sistema de Apoio ao Professor (SIAP). Cada professor possui uma conta e ali pode planejar suas aulas por turma, sendo que o sistema possui opções relacionadas com: expectativas de aprendizagem, conteúdos, metodologias e avaliações. Somente dois dos professores disponibilizaram seus planos de aula (P1 e P2), ambos em formato digital.

Para analisar os dados desta pesquisa, utilizamos a Análise de Conteúdo, com base em Bardin (2011), por a considerarmos como a mais adequada para esse tipo de investigação. Por meio da Análise de Conteúdo, o pesquisador busca compreender características, estruturas ou modelos que estarão por trás das mensagens, além de entender o sentido da comunicação e buscar outro significado, outra mensagem, que seja possível ser vista de forma conjunta à primeira, desvelando-as de forma crítica.

As categorias de análise dessa pesquisa foram estabelecidas a posteriori, ou seja, emergiram dos dados, na medida em que eles foram explorados. Com base nas entrevistas, as categorias referentes à visão dos professores foram: a metodologia de ensino de Estatística e a aprendizagem dos estudantes; vínculos do conteúdo estatístico com situações do cotidiano dos estudantes e a construção dos conceitos; e conteúdos de Estatística priorizados e o critério dessa seleção. Todos os dados foram apresentados dialogicamente, à luz de teorias explicativas que serviram de suporte para nossas interpretações. Assim, inferências foram realizadas para chegar a interpretações claras e objetivas das descrições do objeto de estudo.

\section{Uma Análise da Realidade Investigada}

No que se refere à relevância do planejamento para o processo educacional, há consenso entre os autores. Moretto 
(2007) concebe o ato de planejar como uma organização das ações pedagógicas. A ação de planejar subordina-se à natureza da atividade educativa, que é determinada por uma intencionalidade e envolve: os objetivos, os valores, as atitudes, os conteúdos e a ação dos educadores e educandos. Nesse sentido, Luckesi (2001, p. 108) afirma que:

O planejamento não será nem exclusivamente um ato político-filosófico, nem exclusivamente um ato técnico; será sim um ato ao mesmo tempo político- social, científico e técnico: político-social, na medida em que está comprometido com as finalidades sociais e políticas; científico, na medida em que não se pode planejar sem um conhecimento da realidade; técnico, na medida em que o planejamento exige uma definição de meios eficientes para se obter resultados.

Ao analisar os planos de aula dos professores, foi possível notar que todas as expectativas de aprendizagem referentes à Estatística, que estão presentes no currículo referência do estado de Goiás, foram elencadas; porém, sem uma linha sequencial de organização dos conteúdos. Por exemplo, P1 institui como expectativa da primeira aula "analisar informações em gráficos e tabelas", e P2, "compreender os conceitos básicos da Estatística". Algumas razões podem ter levado os professores a planejar os conteúdos de forma não sequencial, tais como: trabalhar os conteúdos inicialmente de forma analítica e, assim, ir apresentando e discutindo os principais conceitos estatísticos que ali estão agregados; não querer seguir o currículo e planejar desse modo pode ser compreendido como forma de subversão às imposições colocadas pelo sistema; ou, até mesmo, não ter elaborado o planejamento antecipadamente, não observando essa sequência lógica.

No entanto, ao verificar os protocolos de registro das observações das aulas, constatamos que P1 iniciou falando sobre os conceitos básicos da Estatística, como população, amostra e frequência, seguindo o livro didático. Vemos que ele não seguiu o planejado, visto que em seu plano constava para a primeira aula "analisar informações em gráficos e tabelas". Já P2 propôs em sala, na primeira aula, o conteúdo de medidas de tendência central, e no seu plano constava "compreender os conceitos básicos da Estatística” e, assim como P1, não seguiu o que havia planejado.

Quanto à importância de o professor organizar e planejar suas atividades diárias, Hoffmann (2001) reitera que, com base no planejamento, esse profissional conseguirá refletir sobre suas ações pedagógicas e metodológicas, bem como estabelecer uma sequência de conteúdos. Ao solicitarmos esses planos no período de observação, os professores informaram que ainda não haviam elaborado e nem cadastrado no sistema, confirmando nossa conjectura, de que os planos de aula não foram elaborados com antecedência e, além disso, nos foram disponibilizados ao findar das observações das aulas.

Outro aspecto a ser ressaltado é que nem todos os conteúdos estatísticos, propostos nas orientações e diretrizes curriculares brasileiras para o Ensino Médio, compõem o currículo referência do estado de Goiás. A despeito da vasta quantidade de conteúdos relacionados à Estatística constante do referido currículo, as medidas de dispersão (desvio padrão, variância e desvio médio) não são mencionadas no documento. Teoricamente, esses conceitos não foram incluídos no currículo para serem abordados, devido ao fato de eles demandarem um tratamento minucioso em suas análises e os conteúdos estatísticos serem obrigatoriamente trabalhados em um único bimestre, o que demandaria ainda mais tempo, considerando a quantidade de conteúdo que é necessário trabalhar no decorrer do Ensino Médio. A complexidade desses conceitos não permitiria a realização das análises e testes comparativos que eles demandam.

Ademais, as orientações curriculares nacionais reiteram que, ao se trabalhar com Estatística no Ensino Médio, é necessário intensificar a compreensão sobre as medidas de posição (média, moda e mediana) e as medidas de dispersão (desvio médio, variância e desvio padrão), abordadas de forma mais intuitiva no ensino fundamental (Brasil, 2006). Além disso, é necessário que os estudantes saibam obter médias e avaliar desvios de conjuntos de dados ou informações de diferentes naturezas, utilizando essas informações para fazer inferências sobre situações vivenciadas por eles em seus contextos (Brasil, 2002).

Ainda que as medidas de dispersão não estejam contempladas no currículo referência do estado, observamos que P1 trabalhou o conteúdo em sala de aula. Embora de forma totalmente descontextualizada, o professor apresentou aos alunos as fórmulas do desvio médio, da variância e do desvio padrão e propôs alguns exercícios mecânicos, de substituição de dados na fórmula, não demandando que os alunos pensassem nos resultados, na variação e nos desvios que viriam a realizar em determinado contexto.

Quanto às competências da Educação Estatística (literacia estatística, pensamento estatístico e raciocínio estatístico), notamos que, embora os professores $\mathrm{P} 1$ e P2 tenham descrito no plano todas as expectativas que poderiam ser exploradas, elas não foram trabalhadas de modo a levar os estudantes ao desenvolvimento destas três competências. Quanto à primeira expectativa, que é "compreender os conceitos básicos da estatística: população, amostra e frequência absoluta e relativa", observamos que ela foi contemplada, tanto no plano de ensino quanto na primeira aula de Estatística ministrada por P1. Porém, alguns desses conceitos foram apresentados aos alunos de forma bastante superficial, não dialogando com o contexto em que estão inseridos.

O professor P2, apesar de ter indicado em seu plano de ensino que trabalharia essa expectativa na primeira aula, não apresentou nenhum desses conceitos nessa ou nas aulas seguintes do bimestre em questão. Embora P3 não tenha disponibilizado seus planos de ensino, pudemos verificar, por meio das observações, que o conteúdo de Estatística foi iniciado de forma bastante contextualizada. Os conceitos básicos e 
introdutórios foram abordados de acordo com o contexto dos estudantes, isto é, ao conceituar população e amostra, utilizou como exemplo as turmas de $3^{\mathrm{a}}$ série do Ensino Médio do colégio e a própria sala de aula, respectivamente, sendo essa um subconjunto e parte representativa da população.

Nesse sentido, pensamos que uma proposta envolvendo a literacia estatística poderia ter sido desenvolvida em sala de aula pelos três professores, por meio de textos em que os estudantes pudessem identificar o que seria a população e a amostra naquela situação. Além disso, ao trabalharem a literacia estatística, os estudantes poderiam compreender o que aqueles dados contidos nos textos e situações problemas representariam naquele determinado contexto, que poderia ser o próprio contexto deles ou outro mais amplo, além de perceber e identificar as simbologias e as terminologias próprias da Estatística, conforme discutido por Campos, Wodewotzki e Jacobini (2013).

Com relação às expectativas de aprendizagem que se reportam à interpretação, construção, leitura, resolução de problemas, às inferências e análises de dados e informações estatísticas expressas em tabelas, gráficos e histogramas, todas essas expectativas foram elencadas nos planos de ensino dos professores. P1 e P3 trabalharam alguns dos conteúdos referentes a essas expectativas em sala de aula, mas de forma totalmente contrária ao proposto no currículo e nos enfoques da educação estatística.

P1 deu uma ideia geral aos alunos dos elementos que constituem uma tabela, como: título, cabeçalho, fonte, entre outros, mas não trabalhou a construção de tabelas e gráficos em sala de aula, pois estes já vinham prontos nos exercícios do livro didático utilizado. Observamos que P3 também iniciou a explicação desses conteúdos comentando sobre os elementos constituintes de uma tabela. Em seguida, construiu uma tabela com os alunos, mas que não condizia com um assunto próximo a eles e não foi utilizada em nenhum exercício. Quanto aos gráficos, $\mathrm{P} 3$ pediu que os estudantes pesquisassem em casa o que era um gráfico e os seus tipos (barras, colunas e setores), e levassem tal pesquisa na próxima aula para discussão, o que de fato não ocorreu. Já o professor P2 não trabalhou esses conteúdos em sala de aula.

Ao considerar essas expectativas, avaliamos que algumas situações poderiam ter sido propostas pelos professores em sala de aula para que os conceitos estatísticos pudessem ser mais bem compreendidos pelos estudantes, dando enfoque aos pressupostos da Educação Estatística. Dessa forma, ao terem contato com situações problemas que envolvessem gráficos e tabelas, seja para interpretarem ou construírem, os estudantes teriam a possibilidade de desenvolver a literacia estatística de forma crítica e contextualizada. Desse modo, conseguiriam pensar estatisticamente além do que é proposto pelo professor em sala de aula, teriam uma visão completa dos contextos representados a partir dos gráficos e tabelas, considerando outras possíveis interpretações.

Quanto à resolução de problemas que envolvem o cálculo das medidas de tendência central, todos os professores trabalharam os conceitos em sala de aula, mas não por meio de problemas contextualizados, conforme constava em seus planos de aula. Esses três conceitos foram trabalhados com base em exercícios mecânicos, muitas vezes sem enunciados e com dados aleatórios. Os professores apresentaram as fórmulas e como utilizá-las, e muitos dos exercícios propostos consistiam em simples substituição dos dados nas fórmulas. De acordo com Santana (2012, p. 13):

A aprendizagem da Estatística possui significados que ultrapassam em muito uma prática fundamentada na repetição de exercícios padrão, na qual há o predomínio dos aspectos matemáticos da Estatística, com uma utilização formal e mecanicista de suas noções e técnicas e total abandono da casualidade.

Um trabalho contextualizado, considerando as medidas de tendência central e problemas do cotidiano dos alunos, seria possível de ser realizado em sala de aula, desde que se observassem as competências da Educação Estatística. O raciocínio estatístico viria a ser contemplado ao apresentar problemas estatísticos aos estudantes e direcioná-los a conceber os principais conceitos e resoluções, ao construírem argumentos acerca desses resultados, realizar julgamentos e interpretações de diferentes situações e ao conseguir julgar e interpretar as relações entre as variáveis estatísticas em tabelas e gráficos (Campos, 2007). O pensamento estatístico também poderia ser desenvolvido em meio às práticas pedagógicas ao levar os estudantes a refletir sobre determinada situação problema, interpretar os dados desse problema, e, então, encontrar possíveis soluções plausíveis para a situação.

A prática pedagógica dos professores é de grande importância quando se considera o ensino pautado na criticidade e na autonomia dos estudantes. Diante dessa assertiva, observamos o quão importante é contextualizar os conteúdos em sala de aula, pois essa ação visa construir significados com base no cotidiano, em que se compreende um determinado problema ligado à realidade e busca-se uma interpretação. Nas entrevistas realizadas com os três professores, perguntamos como trabalham a Estatística em sala de aula e se essa forma possibilitava aos alunos a construção de conceitos referentes ao conteúdo, sendo essa a primeira categoria de análise que emergiu: a metodologia de ensino de Estatística e a aprendizagem dos estudantes.

P1 discorreu sobre o uso de reportagens de noticiários, matérias de revistas e jornais como uma metodologia usada no trabalho com a Estatística: "cito exemplos propostos em jornais e falo também da estatística usada por meio de comunicação", e disse alcançar a aprendizagem da maioria dos alunos. De fato, essa metodologia pode mobilizar os alunos de forma significativa, aproximando os contextos que perpassam a vida dos estudantes dos conceitos estatísticos trabalhados na escola. Autores como Magalhães (2015), Santana (2012) e Lopes (2010) falam sobre a presença da Estatística em reportagens impressas e televisivas e ressaltam 
a importância de um trabalho que considere o reconhecimento de determinados conceitos em situações da própria realidade.

Pequenos trechos de notícias que apresentam dados sobre determinada situação corriqueira do dia a dia ou até mesmo uma tabela ou gráfico, que mostre informações próximas à realidade, possibilitam aos estudantes enxergar a relevância dos conceitos estatísticos e atribuir significado a eles. Contudo, não observamos, durante as aulas, esse tipo de abordagem. O professor P1, pela resposta dada, possivelmente saiba da funcionalidade dessa forma de trabalho, mas acaba não trabalhando com ela. Talvez devido ao fato de ter pouco tempo em suas aulas para trabalhar os conteúdos de maneira contextualizada.

P3 demonstra, em sua fala, que acredita que a maneira como está trabalhando a Estatística possibilita aos seus alunos construírem os conceitos em questão, e isso foi verificado por meio das provas aplicadas no decorrer do bimestre: "imagino que estou conseguindo intermediar a construção desses conceitos (...) eles fizeram prova, mas não uma avaliação só com esses conceitos, mas pelo menos eles estão conseguindo aplicar nas provas". Considerar somente as provas como instrumento de avaliação é preocupante, pois apenas esse instrumento não possibilita que todos os estudantes possam expressar sua aprendizagem de forma completa.

Concordamos com Sant'Anna (1995) ao considerar que as avaliações devem ser apresentadas aos estudantes como recursos que lhes possibilitem perceber seu crescimento. Tal instrumento deve contribuir para que eles saibam lidar de forma crítica com os problemas apresentados no dia a dia e capacitá-los a ter iniciativas conscientes. Portanto, é necessário que essa avaliação não seja pautada somente em provas, mas em outros instrumentos propostos pelo professor, considerando todo o percurso de construção do aprendizado dos estudantes.

Mesmo que P3 também tenha mencionado que consegue constatar a construção dos conceitos estatísticos pelos alunos, baseando-se na aplicação de provas, verificamos, por meio das observações realizadas durante as aulas, que ele não utilizou somente esse instrumento de avaliação no decorrer do bimestre. Observamos que, em algumas aulas, ele solicitou aos estudantes pesquisas sobre os diferentes tipos de gráficos, porém, a pesquisa foi recolhida e nenhum comentário foi feito a respeito, e a finalidade desse trabalho não foi explicada aos alunos.

Perguntamos também aos professores, por meio das entrevistas, se eles consideravam que os estudantes conseguiam estabelecer relações entre os conceitos estudados durante as aulas e o cotidiano, sendo a segunda categoria estabelecida: vínculos do conteúdo estatístico com situações do cotidiano dos estudantes e a construção dos conceitos. Todos responderam que sim. P1 disse que via o interesse da maioria da sala na resolução de problemas relacionados à Estatística, porém, isso não foi percebido durante as observações das aulas. Víamos os alunos dispersos e pouco participativos e a cada aula o professor trabalhava um novo conceito, seguido de exercícios mecânicos, totalmente distantes de situações cotidianas.

O professor P2, ao afirmar que seus alunos conseguiam relacionar os conceitos estatísticos com o cotidiano, exemplificou como contextualizava os conteúdos, citando o caso de um vendedor que precisa saber a média de lucros e vendas de uma loja. Essa abordagem contextualizada também não ocorreu durante as aulas observadas, divergindo do proposto nas Orientações Curriculares para o Ensino Médio (Brasil, 2006), em que a contextualização deve ser vista como um dos instrumentos que favoreça a construção de significados pelo aluno em todo o processo de ensino e aprendizagem, proporcionando articulações dos conceitos com suas práticas sociais.

Já P3 justificou sua resposta com base em uma pesquisa realizada pelos alunos durante suas aulas. Observamos que, em uma delas, $\mathrm{P} 3$ pediu que os alunos fizessem uma pesquisa em casa sobre a quantidade de dias e horas dedicadas aos estudos para o Exame Nacional do Ensino Médio (Enem), pois, na aula seguinte, iriam construir tabelas e gráficos com base nessas informações.

Sobre a importância de trabalhar assuntos do contexto por meio de gráficos e tabelas, é mencionado nas Orientações Curriculares para o Ensino Médio:

(...) as planilhas eletrônicas, mesmo sendo ferramentas que não foram pensadas para propósitos educativos, também podem ser utilizadas como recursos tecnológicos úteis à aprendizagem matemática. (...) Também oferecem um ambiente apropriado para trabalhar com análise de dados extraídos de situações reais. É possível organizar atividades em que os alunos têm a oportunidade de lidar com as diversas etapas do trabalho de análise de dados reais: tabular, manipular, classificar, obter medidas como média e desvio padrão e obter representações gráficas variadas. (Brasil, 2006, p. 89).

No entanto, P3 não levou os estudantes para o laboratório de informática, mas levou o próprio notebook para a sala de aula, separando os alunos em grupos e chamando-os para verem como se construía tabelas e gráficos. Com essa prática, P3 não ofereceu a oportunidade de os estudantes construírem suas próprias tabelas e gerarem gráficos com as informações por eles pesquisadas. Apesar da boa intenção do professor com essa proposta, em que alguns alunos se interessaram e perceberam as relações das informações contidas nos gráficos e sua própria realidade, foi nítido que a maioria dos alunos não realizou a atividade, pois estavam dispersos e confusos com essa metodologia, que poderia ter sido mais bem planejada. Observamos que P3 teve que mudar seu planejamento de última hora, pois, segundo ele, havia se esquecido de fazer a reserva do laboratório na coordenação da escola.

Outra questão abordada na entrevista, relacionada à elaboração do plano bimestral, consistia em saber quais conteúdos de Estatística foram priorizados pelos professores e o porquê dessa escolha, sendo essa a terceira categoria de 
análise: conteúdos de Estatística priorizados e o critério dessa seleção. P3 afirmou ter priorizado os conceitos estatísticos seguindo o currículo do estado que a ele foi disponibilizado, visto que o considera como exigência mínima para a aprendizagem dos estudantes: “(...) na verdade eu recebi a matriz com os conteúdos que é o currículo formal, e eu coloquei todos os conteúdos que estavam ali, pois eu penso que o currículo que está ali é o mínimo". Os currículos de Matemática, no Brasil, ainda estão formatados, segundo Lopes e Macedo (2011), dentro de uma perspectiva acadêmica, que não permite o diálogo entre as realidades cotidianas e os conteúdos neles apresentados. E é nesses moldes que a Estatística se faz presente no currículo referência do estado de Goiás, com pouca abertura para o diálogo cultural e cotidiano.

É importante reconhecer que P3 abordou todos os conceitos elencados no currículo, iniciando com os conceitos estatísticos, conforme descrito em sua fala: “(...) eu quis trazer primeiro os conceitos, eu tentei trabalhar bem os conceitos de amostra, população, de pesquisa". Porém, mesmo trabalhando os conceitos de frequência, tabelas, gráficos e as medidas de tendência central, esses, em sua maioria, foram abordados de forma descontextualizada. Ponderamos que esse problema poderia ter sido minimizado se os três professores trabalhassem o currículo, adotando epistemologias diferentes das concepções pautadas no positivismo. Nesse sentido, eles deveriam considerar a realidade de seus alunos, tomando esse currículo prescrito e imposto como uma matéria-prima de recriação e contestação (Moreira \& Silva, 2005).

P1, em sua fala, julgou importante trabalhar a porcentagem. Concordamos com ele, pois, mesmo não sendo um conceito específico da Estatística, a porcentagem pode ser utilizada como ferramenta para possibilitar o entendimento de muitos de seus conceitos. A construção de tabelas e gráficos também foi citada pelo professor, conceitos esses trabalhados de forma rápida nas aulas observadas. Nesse sentido, Malara (2008) comenta sobre a importância de um trabalho sem pressa quanto à construção de gráficos e tabelas em sala de aula, pois tal tarefa não é fácil de ser realizada. A autora destaca que grande parte dos professores dedica pouco tempo para essa parte da Estatística, acreditando ser uma tarefa simples e, na verdade, não é, pois demanda dos estudantes lidar com dados, retirados de um determinado contexto, e a articulação desses com outros conceitos estatísticos.

Tanto P1 quanto P2 disseram priorizar, em suas aulas, a média, a moda, a mediana, os gráficos e as tabelas: “como você observou nas minhas aulas, priorizei a mediana, a moda e a média e gráficos" (P2); "o aluno tem que saber analisar e construir gráficos e tabelas, trabalhar assuntos relacionados com média, que é um assunto do dia a dia, mediana e moda, por isso trabalhei esses assuntos (P1)". No entanto, as observações mostram que o trabalho pedagógico foi desenvolvido de formas diferentes. Enquanto P2 trabalhou somente esses conceitos durante todo o segundo bimestre, P1 trabalhou somente as medidas de tendência central e em apenas duas aulas, de modo bastante rápido e com poucos exercícios, abordando outros assuntos nas aulas posteriores.

Lopes (2010) afirma que o estudante, ao se munir da habilidade de analisar criticamente e relacionar os dados apresentados com situações do cotidiano, compreende esses conceitos de forma prática. Reitera, ainda, que esses conceitos devem ser aprofundados no Ensino Médio, pois essas ideias já foram trabalhadas no Ensino Fundamental e, na etapa final da escolarização básica, deve-se priorizar um estudo mais analítico sobre os dados em questão. Logo, as informações obtidas nesta pesquisa mostram que nenhum dos três professores considerou essas orientações.

Quanto ao motivo de escolher esses conceitos para trabalhar em sala de aula, somente P1 e P2 responderam e ambos justificaram sua importância devido ao Enem: "Eu priorizei porque são questões que caem mais no Enem. (P2)"; "Para os alunos do $3^{\circ}$ ano tem grande importância pelo Enem. (P1)”. Segundo Andriola (2011, p. 119), essa prova apresenta informações que possibilitam ao estudante "interpretar, inferir, deduzir, comparar, julgar, aplicar e resolver o problema apresentado, deixando de focar exclusivamente o conhecimento dos conteúdos escolares, como o fazia o vestibular". Dessa forma, as questões presentes no Enem requerem do aluno a interpretação e a habilidade de relacionar conteúdos de diferentes disciplinas, o que caracteriza a prova como interdisciplinar.

\section{Considerações Finais}

O professor é colocado, por diversas vezes, como peça central do processo de ensino-aprendizagem dos conteúdos e, por consequência, sua formação é assunto de extrema relevância. A formação de professores é considerada um dos aspectos fundamentais para qualquer processo de mudança educacional. Assim, a busca por uma formação que seja contínua, em que o fazer pedagógico seja pautado na reflexão crítica teoricamente fundamentada, possibilita ao professor transcender suas concepções.

No que se refere à importância da formação de professores em Educação Estatística, salientamos que um trabalho pautado no ensino dos principais conceitos estatísticos e na observação e análise de dados de um determinado contexto, possibilita o desenvolvimento crítico, político e social do indivíduo. Hoje, a contribuição do ensino da Estatística ultrapassa os muros das escolas, visto que a reconhecer em situações cotidianas, como em reportagens de jornais ou em pesquisas de opinião, permite aos cidadãos entender determinadas problemáticas, presentes em seu cotidiano, avaliá-las e, por fim, tomar decisões.

Nesta pesquisa, foi perceptível que, por mais que sejam consideradas as expectativas de aprendizagem relacionadas aos três enfoques da Educação Estatística (literacia estatística, pensamento estatístico e raciocínio estatístico) nos planejamentos dos professores participantes, o trabalho desenvolvido em sala de aula não as colocou em prática. Assim, os alunos acabaram estudando os conteúdos de forma 
mecânica e foram impossibilitados de desenvolver uma consciência mais crítica e reflexiva acerca de investigações recorrentes na vida cotidiana em que esses conceitos estatísticos estejam envolvidos.

Os dados obtidos por meio das entrevistas com os professores, com relação aos conteúdos e conceitos trabalhados em sala de aula, permitem afirmar que eles priorizaram determinados conceitos estatísticos por serem cobrados nos vestibulares e provas do Enem, ou por estarem presentes no currículo que lhes é apresentado e que precisam cumprir. Mediante a fala dos professores, percebemos que eles não tinham a intenção de fazer um trabalho baseado na contextualização desses conceitos, muito menos promover um estudo de forma crítica. Por mais que afirmaram trabalhar a Estatística relacionada ao cotidiano dos estudantes, ela foi trabalhada de forma tradicional, muitas vezes utilizando apenas o livro didático e os exercícios baseados em fórmulas prontas, visando somente um resultado, o qual não é analisado pelos estudantes.

Reconhecemos que os professores traçaram o objetivo de cumprir determinada ementa de forma estanque e tradicional, pautando suas avaliações nessa perspectiva, devido à sobrecarga do trabalho exercido. Logo, por mais que saibamos da importância de um trabalho que resgate o interesse dos estudantes e que os professores poderiam ser mediadores dessa ação, não podemos deixar de levar em consideração a desvalorização, a sobrecarga de trabalho, a pressão do sistema e a má formação desses profissionais, pois são aspectos que afetam a prática docente.

No entanto, é preciso levar em consideração que esses professores podem não ter tido a oportunidade de ter contato com essas abordagens em sua formação inicial e, por razões econômicas ou temporais, não conseguem investir em uma formação continuada. Essas questões ultrapassam o querer desses profissionais e perpassam por políticas educacionais relacionadas à formação e ao reconhecimento de seu papel frente à educação escolar. Assim, consideramos necessária uma formação continuada de professores com enfoque na Educação Estatística crítica e contextualizada, visto ser uma área de extrema relevância social ao possibilitar o desenvolvimento crítico, político e social dos sujeitos.

\section{Referências}

Andriola, W. B. (2011). Doze motivos favoráveis à adoção do Exame Nacional do Ensino Médio (ENEM) pelas Instituições Federais de Ensino Superior (IFES). Ensaio: aval. pol. públ. Educ., 19(70), 107-126. https://dx.doi.org/10.1590/S010440362011000100007

Bardin, L. (2011). Análise de conteúdo. Lisboa: Edições 70.

Batanero, C. et al. (2013, julio). El sentido estadístico y su desarrollo. Números: Revista Didáctica de las Matemáticas, 83. Barcelona: Sociedad Canaria Isaac Newton de Profesores de Matemáticas, pp. 7-18

Bogdan, R. C., \& Biklen, S. K. (2006). Investigação qualitativa em educação: uma introdução à teoria e aos métodos.
Portugal: Porto Editora.

Brasil. Ministério da Educação. (2018). Base Nacional Comum Curricular: Ensino Médio. Brasília: MEC.

Brasil. Ministério da Educação. (2017). Base Nacional Comum Curricular: Ensino Fundamental. Brasília: MEC.

Brasil. Ministério da Educação. (2006). Orientações Curriculares para o Ensino Médio: Ciências da Natureza, Matemática e suas tecnologias. Brasília: MEC.

Brasil. Ministério da Educação. (2002). Secretaria de Educação Média e Tecnológica. PCN + Ensino Médio: orientações educacionais complementares aos Parâmetros Curriculares Nacionais - Ciências da Natureza, Matemática e suas Tecnologias. Brasília MEC.

Brasil. Ministério da Educação. (1998). Parâmetros Curriculares Nacionais: matemática. Brasília: MEC.

Campos, C. R. (2007). A educação estatística: uma investigação acerca dos aspectos relevantes à didática da estatística em cursos de graduação [Tese de Doutorado em Educação Matemática]. Universidade Estadual Paulista, Rio Claro.

Campos, C. R., Wodewotzki, M. L. L., \& Jacobini, O. (2013). Educação Estatística: teoria e prática em ambientes de modelagem matemática. Belo Horizonte: Autêntica.

Costa, A., \& Nacarato, A. M. (2011) A Estocástica na Formação do Professor de Matemática: percepções de professores e de formadores. Bolema, 24(39), 367-386.

Costa, G. D. F. (2012). A metodologia de projetos como uma alternativa para ensinar estatística no ensino superior. [Tese de Doutorado em Educação]. Arquivo digital de: Universidade Estadual de Campinas (Unicamp), Campinas.

Costa, W. N. G., \& Pamplona, A. S. (2011). Entrecruzando Fronteiras: a Educação Estatística na formação de Professores de Matemática. Bolema, 24(40), 897-911.

D’Ambrosio, B. S., \& Lopes, C. E. (2015, abr.). Insubordinação Criativa: um convite à reinvenção do educador matemático. Bolema, 29(51), 1-17. doi: https://doi.org/10.1590/19804415v29n51a01

Estevam, E. J. G., \& Cyrino, M. C. de C. T. (2014). Educação estatística e a formação de professores de matemática: cenário de pesquisas brasileiras. Zetétike, 22(2), 123-149. doi: https://doi.org/10.20396/zet.v22i42.8646569

Fiorentini, D., \& Lorenzato, S. (2007). Investigação em educação matemática: percursos teóricos e metodológicos. Campinas: Autores Associados.

FIorentini, D., Nacarato, A. M., Ferreira, A. C., Lopes, C. S., Freitas, M. T. M., \& Miskulin, R. G. S. (2002). Formação de professores que ensinam Matemática: um balanço de 25 anos da pesquisa brasileira. Educação em Revista, 36, 137-159.

Gil, A. C. (2008). Métodos e técnicas de pesquisa social. São Paulo: Atlas.

Giroux, H. A. (1997). Os professores como intelectuais: rumo a uma pedagogia crítica. Porto Alegre: Artes Médicas.

Godoy, A. S. (1995). Introdução à pesquisa qualitativa e suas possibilidades. Revista de Administração de Empresas, 35(2), 57-63. doi: https://doi.org/10.1590/S003475901995000200008

Hoffmann, J. (2001). Avaliar para promover: as setas do caminho. Porto Alegre: Mediação.

Lakatos, E. M., \& Marconi, M. A. (2003). Fundamentos de metodologia científica. São Paulo: Atlas. 
Lopes, A. C., \& Macedo, E. (2011). Teorias do currículo. São Paulo: Cortez.

Lopes, C. E. (2008, jan./abr.). O ensino da estatística e da probabilidade na educação básica e a formação dos professores. Cad. Cedes, 28(74), 57-73. doi: https://doi. org/10.1590/S0101-32622008000100005

Lopes, C. E. (2010). Os Desafios para a Educação Estatística no Currículo para a Matemática. In C. E. Lopes, C. Q. S. Coutinho, \& S. A. Almouloud (Org.). Estudos e Reflexões em Educação Estatística. (pp. 47-64). Campinas: Mercado das Letras.

Lopes, C. E. (2013). Educação estatística no curso de licenciatura em matemática. Bolema, 27(47), 901-915. doi: https://doi. org/10.1590/S0103-636X2013000400010

Luckesi, C. C. (2001). Avaliação da aprendizagem escolar: estudos e preposições. São Paulo: Cortez.

Magalhães, M. (2015). Desafios do ensino de Estatística na licenciatura em Matemática. In S. P. Samá \& M. P. M. Silva (Org.). Educação Estatística: Ações e estratégias pedagógicas no Ensino Básico e Superior, pp. 41-54. Curitiba: CRV.

Malara, M. B. S. (2008). Os saberes docentes do professor universitário do curso introdutório de estatística expressos no discurso dos formadores. [Tese de Doutorado em Educação Matemática]. Universidade Estadual Paulista, Rio Claro.

Moreira, A. F. B., \&Silva, T. T. (2005). Sociologia e teoria crítica do currículo: uma introdução. In A. F. B. Moreira \& T. T. Silva (Org.). Currículo, Cultura e Sociedade. São Paulo: Cortez.

Moreira, H., \& Caleffe, L. G. (2006). Metodologia da pesquisa para o professor pesquisador. Rio de Janeiro: DP\&A.

Moretto, V. P. (2007). Planejamento: planejando a educação para o desenvolvimento de competências. Petrópolis: Vozes.

Oliveira, A. F. de, \& Rosa, D. E. G. (2020). A Estatística no
Ensino Médio: em busca da contextualização. Zetetiké, 28, e020006. doi: https://doi.org/10.20396/zet.v28i0.8657024

Pamplona, A. S., \& Carvalho, D. L. (2011, dez.). A Educação estatística e as relações de poder em comunidades de prática. Bolema, 24(39), 351-366.

Pimenta, S. G. (1997). Formação de professores - saberes da docência e identidade do professor. Revista da Educação da Aec do Brasil, 104, 45-61. doi: https://doi.org/10.14572/ nuances.v3i3.50

Samá, S., Cazorla, I., \& Amorim, M. E. (2019). Metodologias Ativas no ensino de Estatística nos cursos de licenciatura. In C. E. Lopes, M. Porciúncula, \& S. Samá (org.). Perspectivas para o ensino e a aprendizagem de Estatística e Probabilidade, pp. 195-220. Campinas, SP: Mercado das Letras.

Sant'Anna, I. M. (1995). Por que avaliar? Como avaliar? Critérios e instrumentos. Petrópolis: Vozes.

Santana, M. S. (2012). Estatística para professores da educação básica: conceitos e aprendizagem para a cidadania. Curitiba: CRV.

Tardif, M. (2012). Saberes docentes e formação profissional. Petrópolis: Vozes.

Triviños, A. N. S. (2013). Introdução à pesquisa em ciências sociais: a pesquisa qualitativa em educação. São Paulo: Atlas.

Viali, L. (2008). O ensino de Estatística e Probabilidade nos cursos de Licenciatura em Matemática. XVIII Simpósio Nacional de Probabilidade e Estatística (SINAPE). São Pedro/SP.

Wodewotzki, M. L. L., \& Jacobini, O. R. (2004). O Ensino de Estatística no Contexto da Educação Matemática. In M. A. V. Bicudo, \& M. C. Borba (org.). Educação Matemática: Pesquisa em Movimento, pp.232-249. São Paulo: Cortez. 